\title{
ANÁLISE DO EVENTO HIDROMETEOROLÓGICO EXTREMO OCORRIDO EM JANEIRO DE 2010 NA BACIA HIDROGRÁFICA DO RIO FORQUETA
}

\author{
Guilherme Garcia de Oliveira ${ }^{1}$, Taísa Flores ${ }^{2}$, Nestor Antonio Bresolin Junior ${ }^{3}$
}

\begin{abstract}
Resumo: Em janeiro de 2010 ocorreu a maior enxurrada já observada na Bacia Hidrográfica do Rio Forqueta, causando sérios impactos em diversos municípios localizados na região. Tal enxurrada objetivou o presente estudo, onde buscou-se apresentar uma análise integrada desse evento extremo hidrometeorológico, com ênfase na dinâmica meteorológica associada à precipitação intensa, nos aspectos morfométricos relacionados às áreas de movimentos de massa e nos fenômenos hidrológicos resultantes do evento. A análise foi fundamentada principalmente no uso de dados obtidos por sensoriamento remoto, dados hidrometeorológicos e relatos obtidos em expedições de campo. Posterior averiguação dos dados constatou-se uma forte influência de Jatos de Baixos Níveis e um corredor de umidade proveniente de noroeste, associada a um centro de baixa pressão na Região do Chaco. Esse mecanismo atmosférico gerou uma precipitação acumulada superior a $250 \mathrm{~mm}$ em $24 \mathrm{~h}$. Concluiu-se que a chuva deflagrou uma sequência de deslizamentos e corridas de detritos nos vales do Rio Fão e Arroio Tereza. Esse material pode ter se acumulado e bloqueado o canal, formando barreiras naturais e promovendo o acúmulo de água e sedimentos a montante. Em seguida, esses barramentos devem ter se rompido, resultando em uma forte enxurrada nos vales dos rios Fão e Forqueta.
\end{abstract}

Palavras-chave: Desastres naturais. Movimentos de massa. Enxurradas.

\section{ANALYSIS OF THE EXTREME HYDROMETEOROLOGICAL EVENT THAT OCCURRED IN THE FORQUETA RIVER BASIN IN JANUARY 2010}

\begin{abstract}
In January 2010 occurred the most intense flash flood ever observed in the Forqueta River Basin, causing serious impacts in several locations. This event encouraged this study to search and develop an integrated analysis of this extreme hydrological event, emphasizing the meteorological dynamics associated to the intense precipitation, to the morphometric aspects related to the landslides areas and to the resulting hydrological phenomena of the event.
\end{abstract}

1 Geógrafo, Dr. em Recursos Hídricos e Saneamento Ambiental, Professor e Pesquisador da Univates.

2 Graduanda em Engenharia Ambiental, Univates.

3 Graduando em Engenharia Civil, Pontifícia Universidade Católica do Rio Grande do Sul - PUCRS. 
The analysis has been found mainly on the use of data obtained by remote sensing, hydrometeorological data and reports gathered during field expeditions. The results show strong influence of Low Level Jets and Humidity Corridor coming from northwest, associated with a Low Pressure System in the Gran Chaco area. This atmospheric mechanism generated an accumulated precipitation higher than $250 \mathrm{~mm}$ in $24 \mathrm{~h}$. It has been concluded that the precipitation unleashed a sequence of landslides and debris flows in the Fão River and Tereza Stream valleys. This material may have been accumulated and obstructed the channel, resulting in natural blockages and leading to water and sediments accumulation upstream. Subsequently, these blockages may have ruptured, resulting in a strong flash flood in the Fão and Forqueta River valleys.

Keywords: Natural disasters. Landslides. Flash Floods.

\section{INTRODUÇÃO}

Os desastres naturais que ocorrem no Brasil são, predominantemente, de origem hidrometeorológica. De acordo com CEPED (2013), as precipitações extremas são alguns dos fenômenos que mais contribuem para a ocorrência de desastres na Região Sul do Brasil. Uma das consequências mais drásticas da ocorrência de chuvas intensas sobre uma determinada região são as inundações, as enxurradas e os movimentos de massa, que ainda podem ser agravadas por ventos fortes, granizo, entre outros (TEIXEIRA; SATYAMURTY, 2004).

O termo desastres pode ser definido como o resultado de eventos extremos, naturais ou provocados pelo homem, sobre uma área vulnerável, na qual causam danos humanos, materiais e ambientais e consequentes prejuízos econômicos e sociais (SANTOS, 2007; OLIVEIRA et al., 2017). A partir de 1970, observou-se grande aumento dos impactos causados por desastres naturais na Região Sul do Brasil, os quais geraram significativos prejuízos socioeconômicos e humanos, pois não só estão mais frequentes como também mais intensos (Marcelino, 2008). Países em desenvolvimento, como o Brasil, são particularmente sensíveis aos desastres naturais. Os motivos para isso são complexos, mas estão ligados ao uso da terra e à desigualdade na distribuição de renda, que acabam por conferir às faixas populacionais de baixa renda os locais de mais alto risco para moradia (BRASIL, 2010). Isso fica claro ao se verificar que os países em desenvolvimento são responsáveis por $95 \%$ das mortes decorrentes de desastres naturais entre 1970 e 2008, de acordo com o IPCC (2012).

Dentre os desastres naturais que ocorrem no Brasil, as inundações, as enxurradas e os movimentos de massa são os que ocorrem com maior frequência e causam os maiores prejuízos à sociedade. Estes eventos correspondem a $73 \%$ das ocorrências e $82 \%$ dos óbitos em função de desastres naturais no Brasil, entre os anos de 1900 e 2006 (MARCELINO, 2008). No intervalo de 2001 a 2016, aproximadamente 1,3 bilhões de pessoas foram afetadas por inundações e enxurradas em todo o mundo, com 285 mil pessoas feridas e 96 mil óbitos, além de prejuízos da ordem de US\$ 400 bilhões. No Brasil, neste mesmo período, foram afetadas 6,8 milhões de pessoas, com mais de 2.500 óbitos e prejuízo aproximado de $\mathrm{R} \$ 20$ bilhões (CRED, 2017). Ainda, de acordo com o mesmo banco de dados, dentre os desastres naturais que ocorrem no Brasil, os movimentos de massa estão entre os que causam o maior número de óbitos. Somente no 
Brasil, os óbitos relacionados aos movimentos de massa e outros fenômenos associados totalizaram 2.351 pessoas em 54 ocorrências registradas no banco de dados do Centre For Research On The Epidemiology Of Disasters.

Tais desastres não podem ser completamente evitados, porém, pode-se realizar algumas medidas de prevenção, a fim de minimizar os danos causados por eles. De acordo com Kobiyama et al. (2004), a prevenção pode ser implementada por meio de medidas estruturais, com a construção de diques ou barragens, entre outras obras hidráulicas, ou por medidas não estruturais, buscando aprimorar o planejamento urbano e o zoneamento de atividades para a utilização de determinado local ou região, bem como por meio do mapeamento de áreas suscetíveis e a implantação de sistemas de alerta.

A Bacia Hidrográfica do Rio Forqueta, um dos principais afluentes do Rio Taquari, apresenta problemas recorrentes no que se refere aos impactos causados por eventos extremos hidrometeorológicos. As grandes inundações e enxurradas observadas na bacia, subsequentes à ocorrência de chuvas intensas, concentram elevados volumes de água que se propagam com alta velocidade nos canais fluviais declivosos. As principais enxurradas nesta região estão relacionadas com o extravasamento das águas dos Rios Fão e Forqueta, principalmente nas áreas urbanas dos municípios de Marques de Souza, Lajeado e Arroio do Meio (FERRI, 1991; OLIVEIRA et al., 2017).

Nos dias 03 e 04 de janeiro de 2010 ocorreu a maior enxurrada que se tem registro na Bacia Hidrográfica do Rio Forqueta. A precipitação acumulada nesses dias superou os $250 \mathrm{~mm}$ em boa parte da bacia, fazendo com que o nível do Rio Forqueta chegasse a subir mais de um metro por hora, causando estragos e desabrigando centenas de pessoas no vale. No município de Marques de Souza, as águas do Rio Forqueta subiram tão rapidamente que não houve tempo para que as comunidades retirassem seus pertences, nem resgatassem seus animais, o que provocou um impacto socioeconômico sem precedentes (CAS, 2015).

Mesmo com a magnitude do evento e seus graves impactos às comunidades ribeirinhas dos rios Fão e Forqueta, esse fenômeno ainda não foi devidamente estudado, nem em relação ao mecanismo atmosférico que provocou a precipitação intensa, nem no âmbito da dinâmica de movimentos de massa e consequentes corridas de detritos e enxurradas. Assim, o objetivo deste estudo é apresentar uma análise integrada do evento extremo hidrológico ocorrido na Bacia Hidrográfica do Rio Forqueta em janeiro de 2010, com ênfase na dinâmica meteorológica associada à precipitação intensa, nos aspectos morfométricos relacionados às áreas de movimentos de massa e nos fenômenos hidrológicos resultantes do evento, bem como os danos e prejuízos associados. 


\section{METODOLOGIA}

O presente estudo consiste em uma análise integrada do evento extremo ocorrido em janeiro de 2010 no vale dos rios Fão e Forqueta (FIGURA 1). Essa análise foi subdividida em quatro etapas, que se refere a diferentes aspectos do evento: i) dinâmica me teorológica; ii) movimentos de massa e análise morfométrica; iii) dinâmica hidrológica e a enxurrada resultante; iv) análise de impactos, danos e prejuízos, como mostra o fluxograma apresentado na Figura 2.

Figura 1 - Mapa de localização da Bacia Hidrográfica do Rio Forqueta

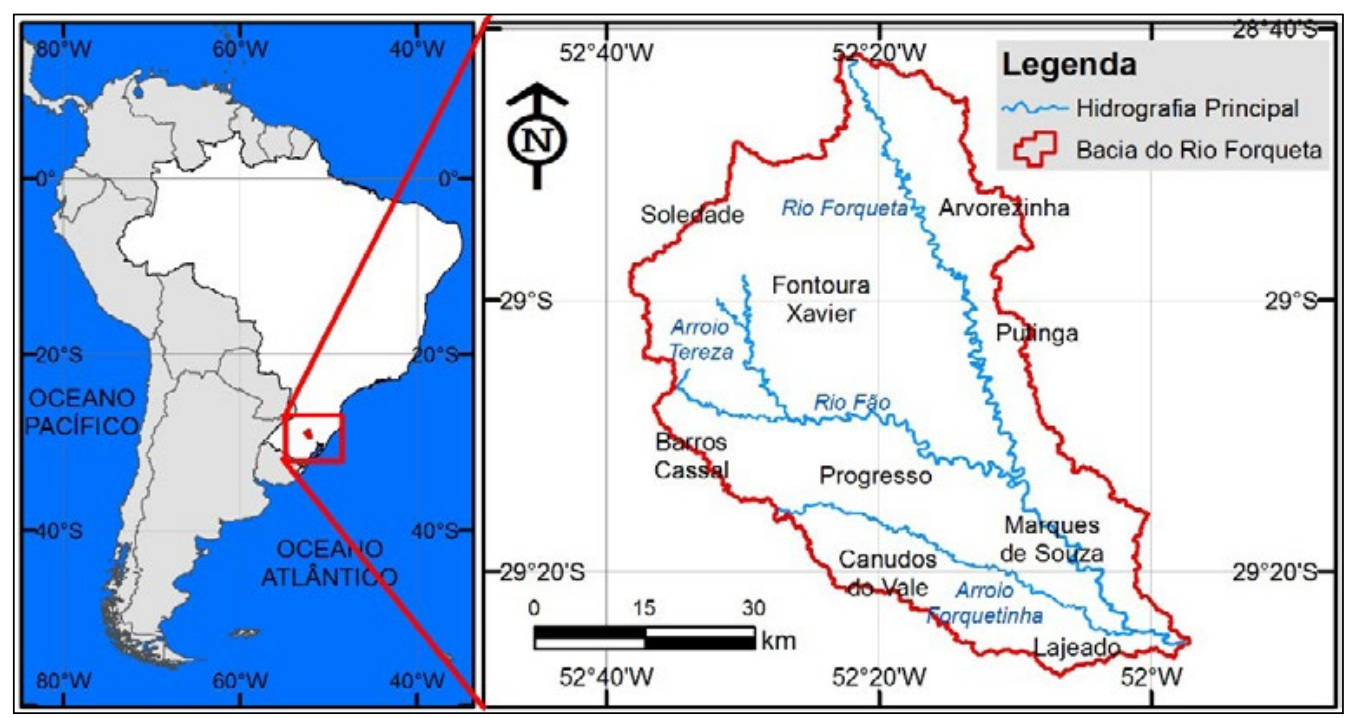

Fonte: do autor (2017).

Figura 2 - Fluxograma das atividades desenvolvidas no estudo

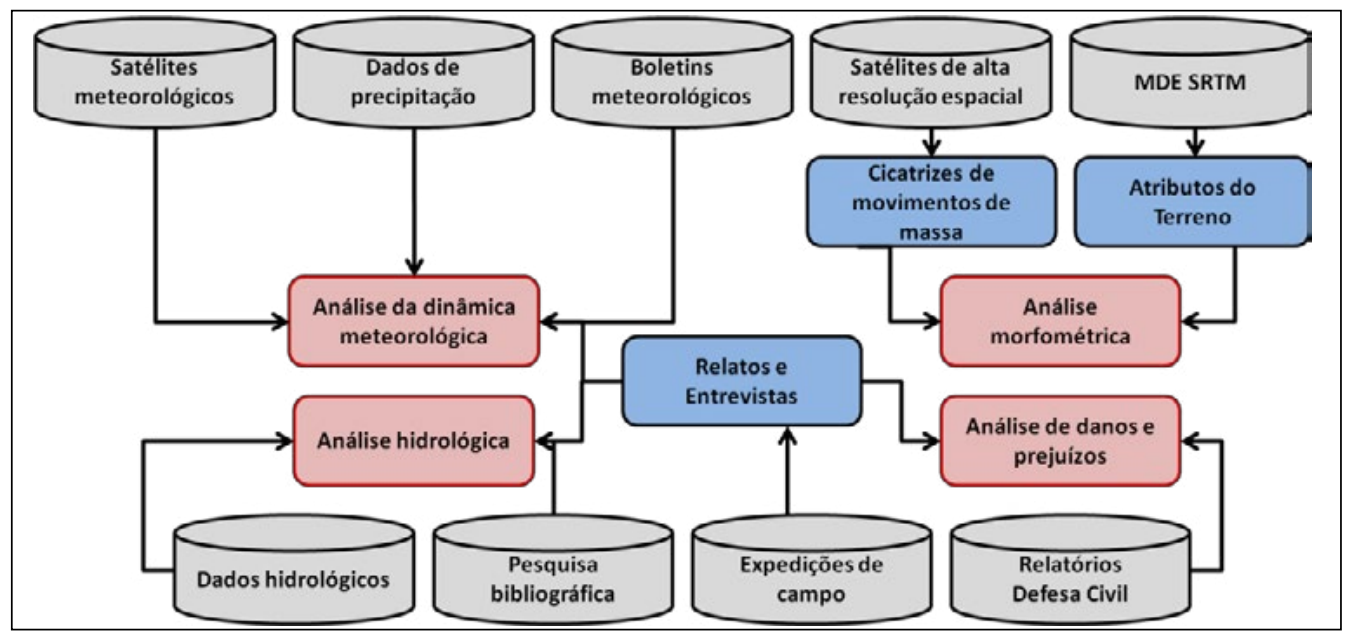

Fonte: do autor (2017). 
Para a análise detalhada dos mecanismos e dinâmica atmosférica associada à precipitação intensa ocorrida nesse evento extremo, primeiramente foram analisados os boletins meteorológicos do Centro de Previsão de Tempo e Estudos Climáticos do Instituto Nacional de Pesquisas Espaciais (CPTEC-INPE) e do Núcleo de Informações Hidrometeorológicas da Univates (NIH-UNIVATES). Além disso, foram compiladas as imagens dos satélites meteorológicos GOES 12, obtidas junto à Divisão de Satélites e Sistemas Ambientais (DSA-INPE), para interpretação da dinâmica atmosférica em um contexto mais continental, possibilitando compreender a gênese do sistema atuante no Rio Grande do Sul. Por fim, foram analisados os dados disponíveis de precipitação, provenientes do Instituto Nacional de Meteorologia (INMET), do Núcleo de Informações Hidrometeorológicas da Univates (NIH-UNIVATES), e de alguns pluviômetros da Defesa Civil e de moradores locais (consultados durante expedições de campo). $\mathrm{O}$ uso conjunto dessas informações permitiu inferir sobre o sistema meteorológico atuante sobre a bacia hidrográfica, bem como caracterizar a precipitação nos contextos temporal e espacial.

A segunda etapa do estudo se refere à organização de um inventário de cicatrizes de movimentos de massa e à extração dos atributos do terreno para uma análise morfométrica das áreas que tiveram esses fenômenos deflagrados naquela ocasião. Após uma rápida investigação em campo e em mídias locais, foi relatada a ocorrência de deslizamentos no segmento do Alto Rio Fão. Esses relatos serviram de referência para uma investigação detalhada em imagens de alta resolução espacial, disponíveis no aplicativo Google Earth. Assim, analisando imagens pré-evento (do ano de 2008) e pós-evento (do ano de 2012) foram identificadas muitas cicatrizes, as quais foram inventariadas e algumas delas validadas em expedições de campo. Os polígonos de cicatrizes foram transformados para o formato de pontos (cada polígono foi preenchido por uma malha regular de pontos, com mesma resolução do modelo digital de elevação, $\mathrm{MDE})$, tendo em vista a necessidade de se extrair o maior número de informações de uma única cicatriz e ampliar o conjunto amostral. As amostras foram segmentadas em duas zonas, que apresentam características distintas: i) zona de ruptura e deslizamentos; ii) zona de corridas e acúmulo de detritos.

A partir dos dados Shuttle Radar Topography Mission (SRTM), disponíveis no portal Earth Explorer, foram extraídos os seguintes atributos numéricos do terreno: i) altitudes; ii) declividades; iii) curvaturas horizontal e vertical do terreno; iv) orientação do terreno; v) distância da hidrografia; vi) distância dos topos de morros e linhas de cumeada; vii) fator topográfico (LS); viii) índice de profundidade do vale (VD). A relação entre esses atributos e o conjunto de amostras de cicatrizes de movimentos de massa foi analisada espacialmente, resultando em uma análise morfométrica, por meio de estatísticas espaciais, buscando-se identificar os limiares de cada variável em relação à ocorrência de movimentos de massa. Além disso, as cicatrizes foram analisadas em relação à área, comprimento e largura.

A terceira etapa consiste na análise das consequências hidrológicas que se resumem em enxurradas e inundações nos vales dos rios Fão e Forqueta. Para tanto, foram 
analisados os dados fluviométricos disponíveis (Hidroweb; PCH Salto Forqueta Certel Energia) e uma revisão de estudos anteriores que realizaram uma breve análise dos aspectos hidrológicos do evento de 2010. O principal deles, o estudo apresentado por Cas (2015), que analisou por meio de modelagem hidrológica a pequena influência dos barramentos da bacia hidrográfica para a atenuação da cheia. Além disso, foram realizadas expedições à campo para verificar com os moradores as principais áreas atingidas e ter uma dimensão da magnitude e duração da enxurrada.

Por fim, buscando uma avaliação preliminar dos impactos, danos e prejuízos, foram compilados relatos e entrevistas de campo, consulta a mídias locais, com o relatório da Def esa Civil que informa alguns dados em relação aos danos, vítimas e número de pessoas atingidas. A integração dessas informações permitiu fazer um balanço sobre as perdas e identificar espacialmente as principais atividades afetadas.

\section{RESULTADOS E DISCUSSÕES}

De acordo com os dados do INMET, em Soledade, e da Univates em LajeadoRS, a precipitação iniciou no dia 03/01/2010, aproximadamente, entre $18 \mathrm{~h}$ e $19 \mathrm{~h}$. Em apenas 21 horas, o acumulado superou os $200 \mathrm{~mm}$ em Soledade, como indica a Figura 3. O período entre 11:00 e 16:00 do dia 04/01 foi o de precipitação mais intensa, com $106 \mathrm{~mm}$ em apenas cinco horas. Em Soledade, o total acumulado foi de $247 \mathrm{~mm}$, enquanto que em Lajeado o acumulado foi de $189 \mathrm{~mm}$, indicando uma concentração nas áreas de montante da Bacia Hidrográfica do Rio Rolante.

Figura 3 - Precipitação acumulada e desagregada em blocos para o período entre 03/01/2010 e 05/01/2010, em Soledade, RS, na estação automática do INMET

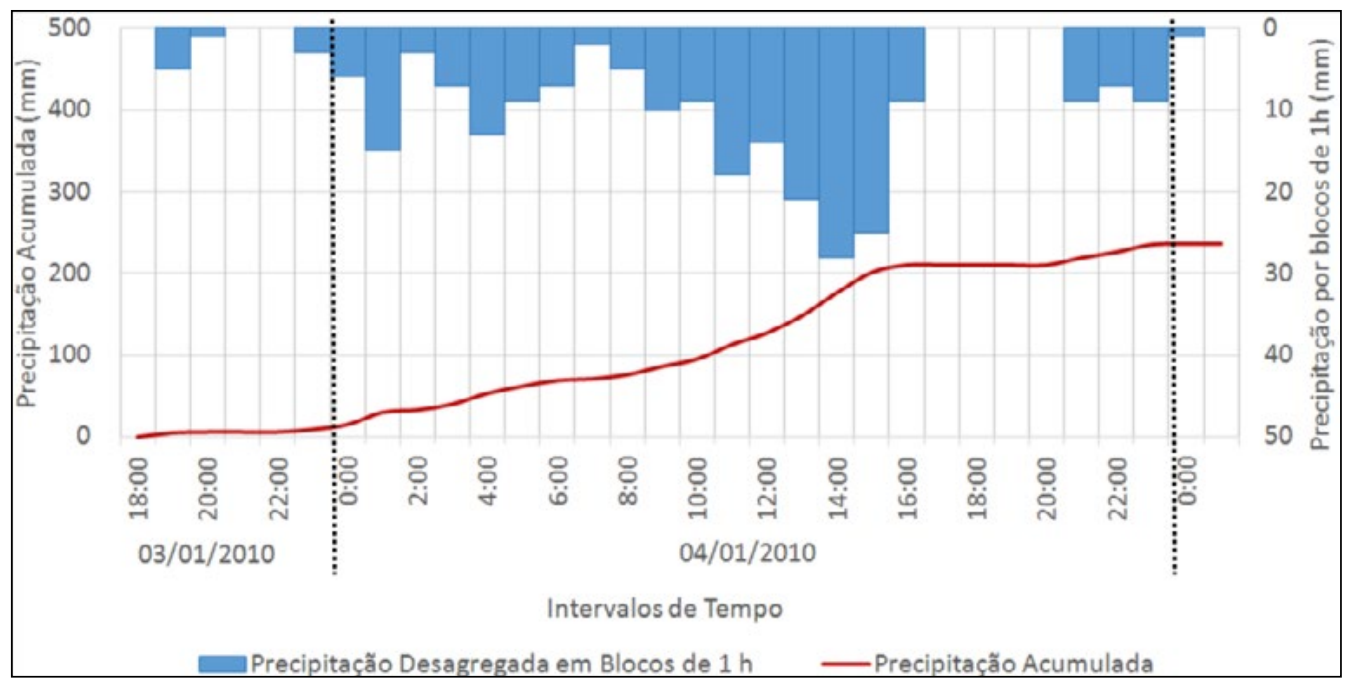

Fonte: do autor (2017). 
Essa concentração fica mais evidente quando realizada uma comparação com os dados disponíveis no banco de dados da Defesa Civil. Em cidades da porção mais a montante, como em Putinga, Progresso, Barros Cassal, Fontoura Xavier e Arvorezinha, a precipitação superou de modo unânime o valor de $200 \mathrm{~mm}$. Em Fontoura Xavier, por exemplo, o acumulado foi de $327 \mathrm{~mm}$ e em Barros Cassal foi de $290 \mathrm{~mm}$. Já na porção mais a jusante, em Marques de Souza, o total acumulado foi de apenas $37 \mathrm{~mm}$. Esses valores foram também validados em campo, em entrevistas com moradores da área rural, que relataram precipitação acumulada superior a $200 \mathrm{~mm}$ em seus pluviômetros, localizados na porção mais alta da bacia.

Na Figura 4 é apresentada uma sequência de imagens do satélite meteorológico GOES 12, obtidas junto ao INPE/CPTEC/DAS, em intervalos de três horas, entre os dias 03/01 e 04/01. Com base nessas imagens, nos boletins meteorológicos do CPTEC e da UNIVATES, e nas condições meteorológicas das estações automáticas, podese constatar uma forte influência de Jatos de Baixos Níveis (JBN) e um corredor de umidade proveniente de noroeste, associada a um centro de baixa pressão localizado na Região do Chaco. Esse mecanismo atmosférico é comum nesse período do ano e pode provocar fortes áreas de instabilidade sobre o Sudeste e o Sul do Brasil, com o deslocamento de massas quentes e úmidas, e sistemas convectivos como os Complexos Convectivos de Mesoescala (CCMs). O sistema convectivo observado nas imagens, durante alguns intervalos de tempo, apresentou topo das nuvens com temperatura inferior a $70^{\circ} \mathrm{C}$ negativos, em uma área suavemente circular com raio superior a $150 \mathrm{~km}(04 / 01$, entre 12:00 e 18:00), o que indica a presença de nuvens com forte desenvolvimento vertical, também conhecidas como cumulonimbos $(\mathrm{Cb})$.

Figura 4 - Imagens do satélite meteorológico

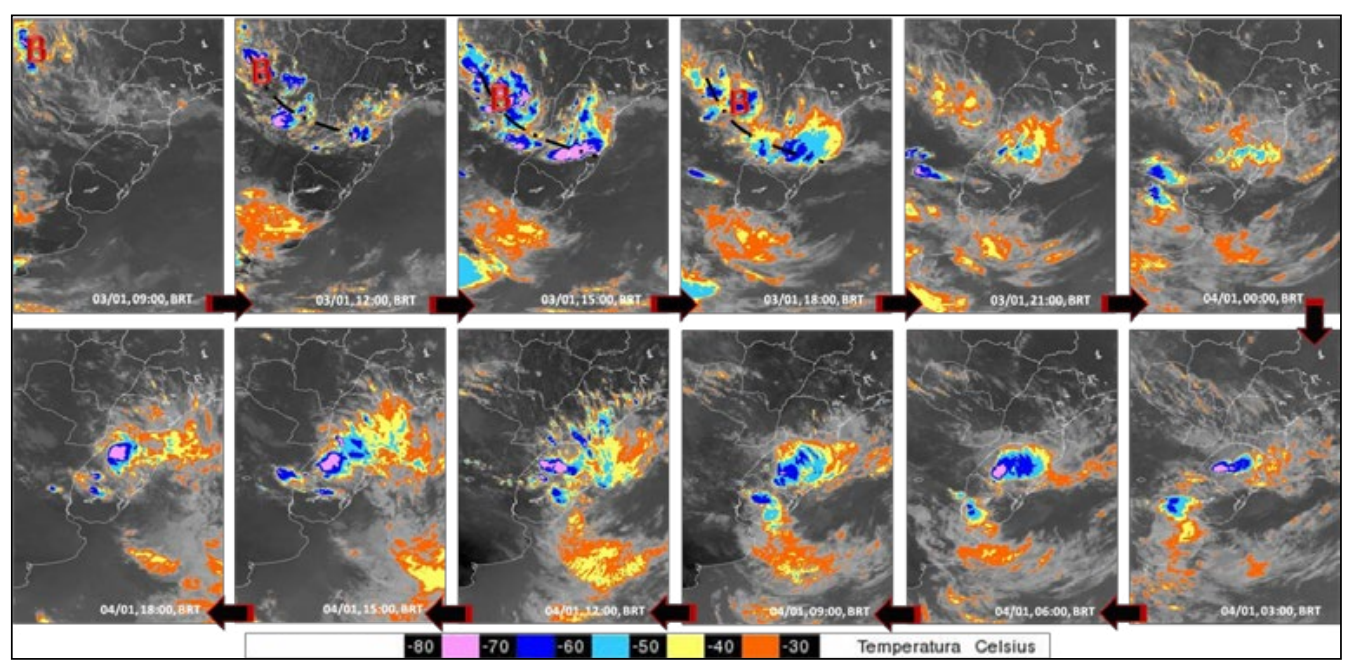

Fonte: do autor (2017). 
Em relação aos movimentos de massa, a investigação nas imagens do Google Earth permitiu identificar 121 cicatrizes nas encostas e extensas manchas de detritos e sedimentos grosseiros no leito dos rios, principalmente no trecho alto do Rio Fão e seus afluentes, como o Arroio Tereza. A área total das cicatrizes mapeadas foi de 27 hectares, com comprimento médio de 250 metros e largura de 20 metros. Em expedição a campo, foi verificada que a profundidade média é inferior a um metro nas cicatrizes visitadas, indicando a predominância de deslizamentos rasos.

Os relatos dos moradores indicam que esses deslizamentos ocorreram quase que simultaneamente, e praticamente todos resultaram em grande acúmulo de detritos no fundo dos vales, provocando a formação de barreiras naturais no leito dos rios, que acumularam em um primeiro momento a água escoada de montante. Algumas das áreas propícias para que isso tenha ocorrido são ilustradas na Figura 5, onde o Arroio Tereza e o Rio Fão possuem um forte controle estrutural com meandros em cotovelos e ângulos retos. Nessas curvas, houve um conjunto de deslizamentos que, ao ocorrerem simultaneamente, podem ter provocado o barramento do rio pelos detritos de solos e rochas e material vegetal das árvores. Esse fenômeno já foi relatado em publicações internacionais, conhecido como Valley Blocking Landslide, existindo inclusive indícios de ter ocorrido também em Rolante, RS, em janeiro de 2017, conforme o relatório apresentado pelo Departamento de Rescursos Hídricos da Secretaria do Ambiente e Desenvolvimento Sustentável do Rio Grande do Sul (DRH-SADS, 2017). 
Figura 5 - Cicatrizes de movimentos de massa e áreas com acúmulo de detritos (em vermelho) do evento extremo ocorrido em janeiro de 2010, em função das declividades (tons de cinza)

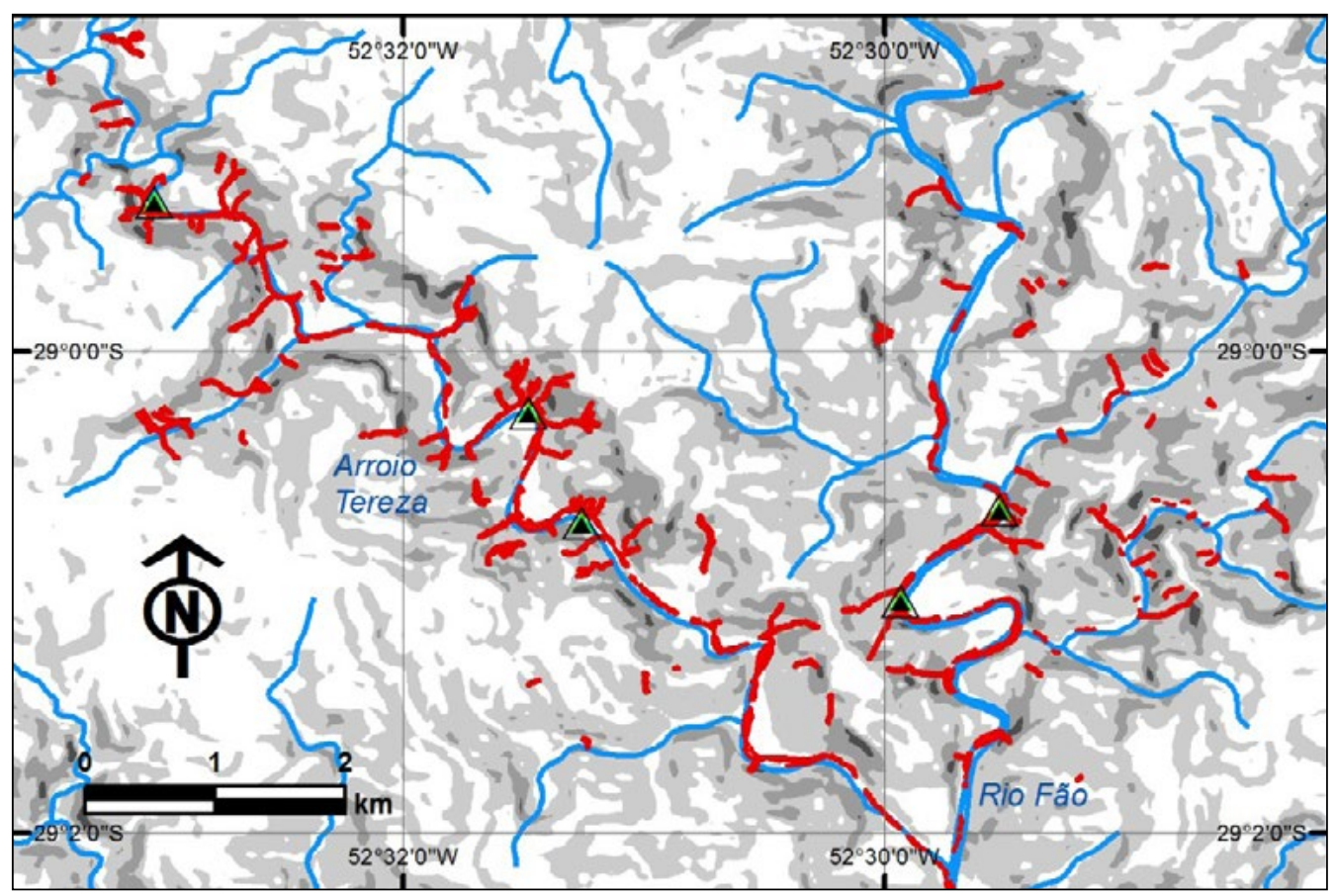

Nota: Os triângulos indicam pontos onde pode ter ocorrido a formação de barreiras naturais no Arroio Tereza e no Rio Fão.

Fonte: do autor (2017).

Em relação à análise morfométrica em pontos localizados nas cicatrizes, pode -se destacar que $90 \%$ das amostras estão localizadas em altitudes entre 330 e $735 \mathrm{~m}$, com média de 535 metros e tendência à distribuição normal. A declividade média das amostras foi de $31^{\circ}$, sendo que apenas $10 \%$ das amostras estão localizadas em áreas com declividades inferiores a $15^{\circ}$, apresentando também um comportamento que segue a distribuição normal. Considerando a curvatura do terreno, $67 \%$ das amostras se localizam em áreas de relevo côncavo, que predominam na primeira metade das encostas, mais próximo das linhas de drenagem. Integrando com a curvatura horizontal, pode-se afirmar que a maior parte das cicatrizes fica em áreas de relevo côncavoconvergente, isto é, em encostas com formato de anfiteatro, com fluxo convergente da água das chuvas. Por fim, em relação à orientação do terreno predominante, as cicatrizes apresentam uma concentração nas vertentes sudeste (SE), sul (S) e sudoeste (SW), que apresentam solos mais úmidos e profundos e vegetação mais densa, em função da menor quantidade de iluminação ao longo do ano nos subtrópicos. 
As evidências de campo, conforme entrevistas erelatos dos moradores, e a modelagem hidrológica realizada por Cas (2015) apontam para o rompimento das barreiras naturais que se formaram ao longo do Rio Fão e Arroio Tereza. Isso porque todos moradores mencionam uma grande "onda" no período da tarde do dia 04/01, após a ocorrência dos deslizamentos a montante. Os moradores do vale do Rio Forqueta, nos municípios de Pouso Novo, Marques de Souza e Travesseiro, relataram que o rio subiu de forma mais rápida do que o normal, chegando a atingir cotas nunca antes registradas pela população. Em alguns pontos do Rio Fão, o nível de enxurrada superou em 20 metros o nível normal, mais que cinco metros acima da maior enxurrada já observada até então.

O estudo de Cas (2015) não considerou a possibilidade de acúmulo de água a montante e o rompimento das barreiras naturais, calculando uma vazão máxima de aproximadamente $4.300 \mathrm{~m} / \mathrm{s}$ em Marques de Souza, considerando apenas a transformação da chuva em vazão e a propagação da onda de cheia pelo método Muskingum-Cunge. Esse valor é muito próximo a uma enxurrada resultante de uma precipitação máxima com tempo de retorno de 30 anos, comparando com o estudo de Oliveira et al. (2017), o que não condiz com o observado na realidade. Esses indícios mostram que possivelmente ocorreu um fenômeno hidrológico diferenciado, possivelmente associado aos deslizamentos, corridas de detritos e acúmulo de material bloqueando o vale a montante. Ao romperem as barreiras naturais, o resultado é uma rápida e violenta onda de enxurrada, que provocou a destruição completa de duas grandes pontes, centenas de edificações, campings, um cemitério, entre outras estruturas.

$\mathrm{Na}$ cidade de Marques de Souza, as águas do Rio Forqueta subiram rapidamente não dando tempo para as pessoas retirarem seus pertences, nem resgatar animais. As propriedades situadas em áreas ribeirinhas, baseadas em agricultura e pecuária, bases da economia deste município, foram destruídas por completo. A enxurrada causou grandes prejuízos materiais em boa parte da cidade ocasionando a falta de água e de energia elétrica (CAS, 2015).

Ao todo, no RS, 112 municípios informaram danos à Defesa Civil nesse evento extremo, totalizando 46.924 pessoas afetadas diretamente, sendo desabrigadas ou desalojadas. De acordo com os dados da Defesa Civil, 50 pessoas ficaram feridas e três foram mortos, estes últimos em Agudo, sobre uma importante ponte que foi destruída pela inundação do Rio Jacuí. Considerando apenas a Bacia Hidrográfica do Rio Forqueta, foram aproximadamente 2.500 pessoas afetadas diretamente, com 35 feridos em Canudos do Vale. Algumas famílias foram resgatadas $\mathrm{n}$ os telhados de suas residências pela Defesa Civil. 


\section{CONCLUSÕES}

Neste estudo foi apresentada uma análise do evento extremo hidrometeorológico que causou graves impactos na Bacia Hidrográfica do Rio Forqueta em janeiro de 2010. A análise realizada em relação ao fenômeno atmosférico, aos movimentos de massa e à dinâmica hidrológica, bem como as evidências observadas em campo, permitiu chegar à conclusão de que as intensas chuvas que ocorreram entre a noite do dia 03/01 e a tarde do dia 04/01 deflagraram uma sequência de deslizamentos e corridas de detritos nos vales do Rio Fão e Arroio Tereza. Esse material pode ter se acumulado e bloqueado o canal, formando barreiras naturais e promovendo o acúmulo de água e sedimentos a montante. Esses barramentos devem ter se rompido em algum momento da tarde do dia 04/01, resultando em uma forte onda de cheia, nunca antes observada pelos moradores localizados a jusante dessa área, nos vales dos rios Fão e Forqueta.

Essa conclusão revela uma condição que pode ser preocupante nas áreas da Serra Geral do Rio Grande do Sul, ainda mais porque um fenômeno semelhante foi relatado e pode ter ocorrido em outra região, na Bacia Hidrográfica do Rio Rolante, em 2017. Os resultados obtidos nesta pesquisa ainda precisam ser aprofundados, com a coleta de novos relatos e medições em campo para estimar o volume de material deslizado pelas encostas, visando modelar e/ou simular o fenômeno que ocorreu em 2010, sendo uma possível continuação para as pesquisas nessa área de estudo. Além disso, pretende-se gerar uma cartografia de suscetibilidade a partir de modelos matemáticos como Redes Neurais Artificiais, para identificar outras áreas com atributos do terreno semelhantes aos locais com cicatrizes de movimentos de massa.

\section{REFERENCIAS}

BRASIL. Segunda Comunicação Nacional do Brasil à Convenção-Quadro das Naç̃̃es Unidas sobre Mudança do Clima. Brasília. 2010. Disponível em: http://www.mct.gov.br/ upd_blob/0213/213909.pdf. Acesso em: 05 jan. 2017.

CAS, R. Estudo da influência da PCH Salto Forqueta na enchente de 4 de janeiro de 2010. Trabalho de Conclusão de Curso - Engenharia Civil, Lajeado: Centro Universitário Univates, 2015.

CEPED - CENTRO UNIVERSITÁRIO DE ESTUDOS E PESQUISAS SOBRE DESASTRES. Atlas brasileiro de desastres naturais 1991 a 2010: Brasil. 2013. Disponível em: http://www.ceped.ufsc.br/wp- content/uploads/2012/01/AMAZONAS_mioloWEB.pdf. Acesso em 16 abr. 2017.

CRED - CENTRE FOR RESEARCH ON THE EPIDEMIOLOGY OF DISASTERS. The international disaster database. 2017. Disponível em: http://www.emdat.be/database. Acesso em: 10 maio 2017.

DRH-SADS - DEPARTAMENTO DE RECURSOS HÍDRICOS - SECRETARIA DO AMBIENTE E DESENVOLVIMENTO SUSTENTÁVEL DO RIO GRANDE DO 
SUL. Diagnóstico preliminar descritivo dos eventos ocorridos no dia 05 de janeiro de 2017 entre as regiões dos municípios de São Francisco de Paula e Rolante/RS. 26p. 2017.

FERRI, G. História do Rio Taquari-Antas. 1a ed. Encantado: Grafen, 1991.

IPCC. Summary for Policymakers. In: Managing the Risks of Extreme Events and Disasters to Advance Climate Change Adaptation. A Special Report of Working Groups I and II of the Intergovernmental Panel on Climate Change. Cambridge University Press, Cambridge, UK, and New York, NY, USA, 2012 pp. 1 -19.

KOBIYAMA, M.; CHECCHIA, T.; SILVA, R.V.; SCHRÖDER, P.H.; GRANDO, Â.; REGINATTO, G.M.P. Papel da comunidade e da universidade no gerenciamento de desastres naturais. In: Simpósio Brasileiro de Desastres Naturais, 1., 2004, Florianópolis. Anais... Florianópolis: GEDN/UFSC, 2004. p. 834-846 (CDROM).

MARCELINO, E. V. Desastres Naturais e Geotecnologias: conceitos básicos. Santa Maria: Instituto Nacional de Pesquisas Espaciais - INPE/CRS, 2008.

OLIVEIRA,G.G.; FLORES, T.; HAETINGER, C.; BRESOLIN JR, N.A.;

ECKHARDT, R.R.; QUEVEDO, R.P. Modelagem hidrológica e geotecnologias para análise de suscetibilidade a inundações e enxurradas em locais com baixa disponibilidade de dados altimétricos e hidrológicos. Artigo submetido para publicação na Revista Geociências (São Paulo, Online). 2017.

SANTOS, R. F. (org.) Vulnerabilidade Ambiental. Ministério do Meio Ambiente (MMA). Brasília, 2007.

TEIXEIRA, M. S.; SATYAMURTY, P. Episódios de chuvas intensas na região sul do Brasil. Parte I: Configuração sinópticas associadas. In: CONGRESSO BRASILEIRO DE METEOROLOGIA, 13. Fortaleza. Anais. 2004. CD-ROM, On-line. (INPE-12104PRE/7450). Disponível em: http://urlib.net/cptec.inpe.br/walmeida/2004/09.21.10.34. Acesso em: 02 nov. 2016. 